\title{
Analisis Video Share to Followers Ratio Tiktok Pada 5 Brand Skin Care Lokal Indonesia Terlaris Tahun 2021
}

\author{
Ni Wayan Eva Agustini \\ wayaneva7@gmail.com
}

\begin{abstract}
TikTok is a social media application launched by a Chinese company. TikTok allows users to create 15 -second videos accompanied by music, filters, and several other creative features. In Indonesia, there are 30.7 million active users, making Indonesia the country with the largest TikTok users in the world. The large number of active TikTok users in Indonesia can certainly provide an opportunity for brands to make the TikTok platform a social media marketing platform. There are 5 Local Skin Care Brands in Indonesia that use TikTok as a marketing platform, namely: Somethinc, N'Pure, Avoskin, White Lab and Ms Glow. The purpose of this study is to calculate the credibility of the account performance of TikTok 5 Local Skin Care Brands in Indonesia. The method used for this research is quantitative exploratory method. The results of this study indicate that SomeThinc skin care gets the first rank and has good account performance credibility.
\end{abstract}

\begin{abstract}
ABSTRAK
TikTok merupakan aplikasi sosial media yang diluncurkan oleh perusahaan asal Tiongkok. TikTok memungkinkan penggunanya membuat video berdurasi 15 detik yang disertai dengan musik, filter, dan beberapa fitur kreatif lainnya. Di Indonesia terdapat 30,7 juta pengguna yang aktif sehingga menjadikan Indonesia sebagai negara dengan pengguna TikTok terbesar di dunia. Maraknya jumlah pengguna TikTok yang aktif di Indonesia tentu dapat memberikan peluang bagi brand untuk menjadikan platform TikTok sebagai platform social media marketing. Adapun 5 Brand Skin Care Lokal di Indonesia yang memanfaatkan TikTok sebagai platform marketing, yaitu : Somethinc, N'Pure, Avoskin, White Lab dan Ms Glow. Tujuan dari penelitian ini yaitu untuk menghitung kredibilitas dari performa akun TikTok 5 Brand Skin Care Lokal di Indonesia. Metode yang digunakan untuk penelitian ini yaitu metode eksploratif kuantitatif. Hasil dari penelitian ini menunjukan bahwa skin care Somethinc mendapatkan peringkat pertama dan memiliki kredibilitas performa akun yang baik.
\end{abstract}

Keyword : Credibility Account TikTok ; Social Media Marketing ; Social Media TikTok ; Video Share to Followers Ratio ; Skin Care Lokal Indonesia. 


\section{PENDAHULUAN}

Seiring dengan kemajuan tekhnologi, maka banyaknya media yang dapat digunakan manusia untuk dijadikan alat dalam berkomunikasi, demikian pula dengan media sosial yang dapat dengan mudah diakses melalui jaringan internet. Pada umumnya fungsi dari media sosial diantaranya untuk berbagi pesan dengan banyak pengguna media sosial itu sendiri,yaitu berupa berita (informasi), gambar (foto) dan juga tautan video. Media sosial tidak hanya dapat di akses di perangkat komputer, tetapi dengan adanya aplikasi di smartphone atau telepon pintar, maka semakin memudahkan masyarakat untuk mengakses media sosial secara mobile sehingga dapat diakses kapanpun dan di manapun.(Susilowati, 2018).

Pada aplikasi Tik Tok ini pengguna dapat membuat video yang hanya berdurasi kurang lebih 30 detik dengan memberikan special effects yang unik dan menarik serta memiliki dukungan musik yang banyak sehingga penggunanya dapat melakukan performa dengan beragam gaya ataupun tarian, dan masih banyak lagi sehingga mendorong kreativitas penggunanya menjadi content creatore. (Merdeka.com, n.d.) Selain itu aplikasi Tik Tok juga dapat memberikan penggunanya untuk dapat menggunakan beragam pecial effect, dan juga musik background dari berbagai artis terkenal dengan berbagai kategori dan juga special effect lainnya yang dapat digunakan secara instan, sehingga dapat membuat video tersebut menarik serta memiliki alunan lagu yang disesuaikan dengan situasi di video tersebut.

Di Indonesia, terdapat 30,7 juta pengguna TikTok yang aktif sehingga menjadikan Indonesia sebagai negara dengan pengguna TikTok terbesar di dunia. Maraknya jumlah pengguna TikTok aktif di Indonesia tentu dapat memberikan peluang bagi brand untuk menjadikan platform ini sebagai platform social media marketing. Cukup banyak akun perushaan-perusahaan terkenal yang ada pada tiktok, contohnya seperti 5 Brand Skin Care Lokal Terlaris tahun 2021 antara lain : Somethinc, N'Pure, Avoskin, Whitelab dan MS Glow (5 Brand Skin Care Lokal Terlaris Tahun 2021., n.d.).

Penelitian ini menggunakan metode eksploratif kuantitatif, dan akan menghitung menggunakan rasio-rasio yang ada pada TikTok. Penelitian ini hanya berfokus untuk menghitung kredibilitas(Eriyanto, n.d.) Video Share to Followers Ratio 5 Brand Skin Care Lokal Indonesia. Tujuan dari penelitian ini adalah mengetahui kredibilitas performa dari akun TikTok 5 Brand Skin Care Lokal Indonesia, menggunakan Video Share to Followers Ratio. 


\section{TINJAUAN PUSTAKA}

Perkembangan teknologi komunikasi di dunia (termasuk Indonesia) dapat membuat perubahan pada sikap dan perilaku penggunanya. Hal ini memunculkan dampak positif dan negatif. Untuk contoh dampak positif: jika pengguna ingin mencari informasi, mereka hanya perlu browsing di internet. Hal ini membuat aktivitas mereka menjadi lebih mudah dan sederhana. Untuk contoh dampak negatifnya: anak-anak dapat mengakses situs porno. Hal ini membuat degradasi/turunnya kepribadian mereka. Jadi, kita harus bijaksana saat menggunakan teknologi.

Melalui perkembangan yang terjadi dari waktu ke waktu menimbulkan maraknya aplikasiaplikasi serta platform media sosial yang bermunculan. Aplikasi yang sangat diminati oleh masyarakat saat ini diantaranya adalah TikTok, Instagram, Twitter, WhatsApp dan yang lain sebagainya. Seiring berjalannya waktu, aplikasi sosial media tersebut dapat menjadi candu bagi kalangan masyarakat. Tidak hanya kalangan remaja yang menggunakan aplikasi sosial media, orang tua bahkan anak-anak juga aktif menggunakan aplikasi sosial media tersebut.(Hanasiah, 2017)

Tik Tok merupakan aplikasi Sosial Media yang menjadi budaya populer di Indonesia mulai awal tahun 2020 ini. Tik Tok sendiri dalam pelafalan bahasa cina di sebut Douyin yang merupakan aplikasi video musik yang pada awalnya digunakan untuk hiburan lipsync lagu oleh penggunanya, aplikasi ini dari berasal dari negeri Tiongkok yang diciptakan oleh ByteDance (Hasiholan et al., 2020)

Di Indonesia Pada tahun 2018 aplikasi ini dinobatkan sebagai aplikasi terbaik di Play store yang dimiliki oleh Google. Tidak hanya itu, Tik Tok juga menjadi kategori aplikasi paling menghibur. Pada Juli lalu Aplikasi buatan China itu sempat diblokir oleh Kementrian Komunikasi dan Informatika (Kominfo) di pertengahan 2018, alasannya karena adanya konten-konten yang negatif, terutama bagi anak-anak. Pemblokiran pada aplikasi ini hanya berlangung seminggu, mulai 3-10 Juli 2018. Aplikasi ini banyak digemari oleh para remaja, anak kecil, bahkan sampai pada orang dewasa yang merasa membutuhkan hiburan.(Adawiyah, 2020) 


\section{METODE PENELITIAN}

Penelitian ini menggunakan metode eksploratif kuantitatif untuk mengetahui kredibilitas dari performa akun TikTok 5 Brand Skin Care Lokal Terlaris Di Tahun 2021.Penelitian eksploratif merupakan penelitian yang bertujuan untuk menggali secara luas tentang sebab-sebab atau hal-hal yang mempengaruhi terjadinya sesuatu dan dipakai manakala kita belum mengetahui. Metode penelitian eksploratif adalah penelitian yang bertujuan untuk memetakan suatu objek secara relatif mendalam (Nurlailiyah, 2016).

Tujuan dari penelitian ini yaitu mengetahui nilai kredibillitas dari performa akun TikTok 5 Brand Skin Care Lokal Terlaris Tahun 2021. Ada beberapa langkah yang harus dilakukan dalam penelitian ini, sehingga mampu menemukan peringkat pertama akun TikTok Skin Care Lokal di Indonesia yang memiliki performa terbaik. Langkah-langkah yang dilakukan pada penelitian ini, diantaranya yaitu;

\section{Melakukan Eksplorasi Pada Website Untuk Menentukan Objek yang Akan Dianalisa.}

Eksplorasi ini dilakukan pada beberapa halaman website yang menyediakan informasi mengenai objek yang akan di teliti(Pintar, n.d.). Setelah ekslorasi selesai dilakukan, sehingga ditemukan nama-nama brand skin care lokal di Indonesia yang akan dijadikan objek analisa. Setelah melakukan eksplorasi pada halaman website, maka langkah selanjutnya yaitu mencari nama akun TikTok dari masing-masing Brand Skin Care Lokal. Pastikan semua brand memiliki akun pada aplikasi sosial media TikTok.

\section{Menghitung Nilai Rata-Rata Variable Dari 5 Brand Skin Care Lokal Terlaris di Indonesia.}

Pada langkah ini, peneliti menghitung nilai variable video comments dan variable video views.Secara teoritis variabel adalah atribut seseorang, atau obyek yang mempunyai "variasi" antara satu orang dengan yang lain atau satu obyek dengan obyek lainnya (Saifuddin Azwar, 2007). Untuk menghitung nilai rata-rata dari variabel video share dan variabel followers yaitu dengan cara mengambil minimal 10 postingan kemudian di hitung sehingga menemukan nilai rata-rata dari masing-masing variabel. 


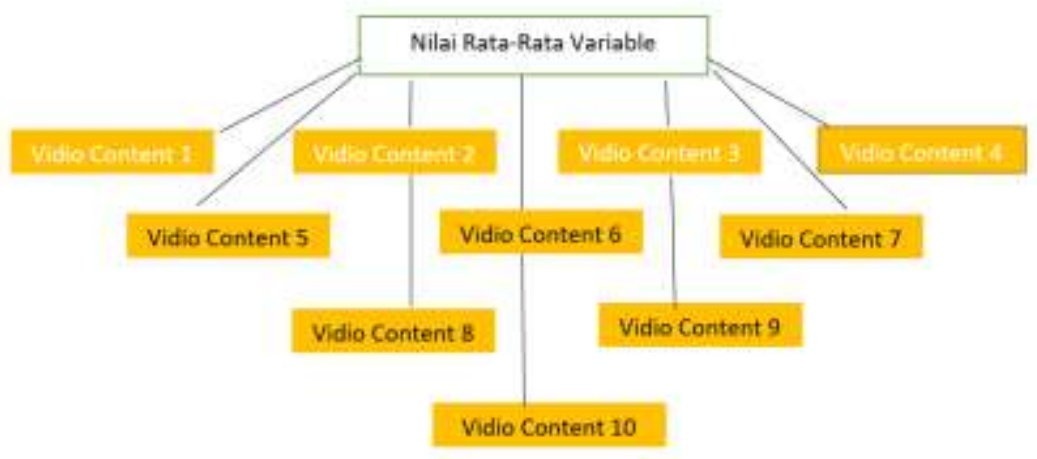

Gambar 1 Analisa Nilai Rata Rata Variabel

\section{Menghitung Nilai Kredibilitas Rasio}

Untuk menghitung nilai kredibilitas dari video share to followers ratio, peneliti menggunakan cara membagi nilai variabel pertama dengan nilai variabel kedua. Jika video share memiliki nilai 1.000 dan followers memiliki nilai 5.000, maka cara menghitungnya yaitu $1.000: 5.000=0,2$. Dengan begitu nilai dari video share to followers ratio adalah 0,2

\section{Menentukan Peringkat Pada Akun TikTok}

Pada langkah terakhir yang dilakukan pada penelitian ini yaitu menentukan peringkat pada masing-masing rasio yang ada. Pada penentuan peringkat perlu melihat karakteristik dari rasio yang di teliti. Jika karakteristik rasio merupakan rendah, maka objek yang memiliki nilai terendah akan mendapatkan angka 5 dan objek yang memiliki nilai tertinggi akan mendapatkan angka 1 . Namun jika rasio memiliki karakteritik tinggi maka objek yang mendapatkan nilai tinggi akan mendapatkan angka 5 dan objek yang mendapatkan nilai terendah akan mendapatkan angka 1. Setelah mendapatkan hasil kredibilitas ratio maka dapat disimpulkan objek yang mana mendapatkan peringkat 1 sampai dengan peringkat 5 . 


\section{HASIL DAN PEMBAHASAN}

Akun TikTok dari 5 Brand Skin Care Lokal Indoneisa Terlaris Tahun2021, diantaranya :

1. Somethincofficial

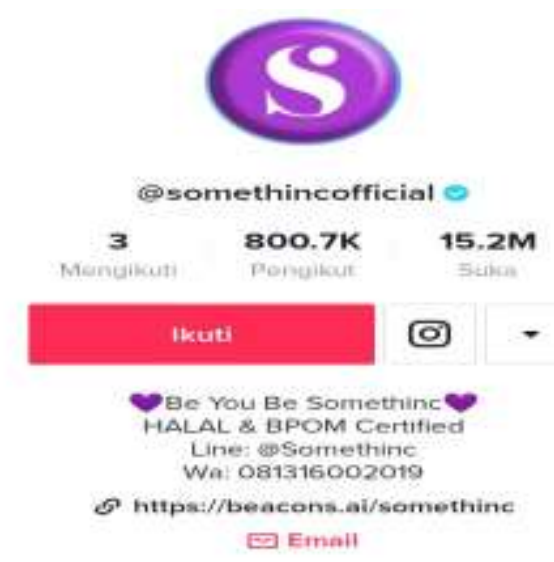

Gambar 1. Akun TikTok Somethincofficial

Sumber : https://vt.tiktok.com/ZSeFLeWrx/ (akses pada 19-10-2021)

2. N'PURE

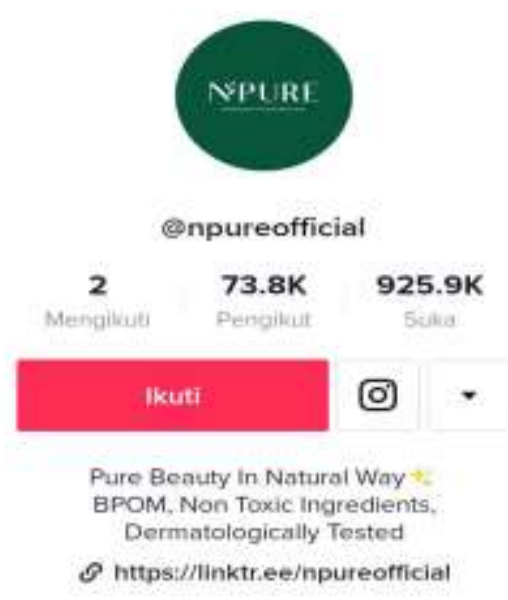

Gambar 2. Akun TikTok N'PURE

Sumber : https://vt.tiktok.com/ZSeF8Ek1G/ (akses pada 19-10-2021) 


\section{Avoskin}

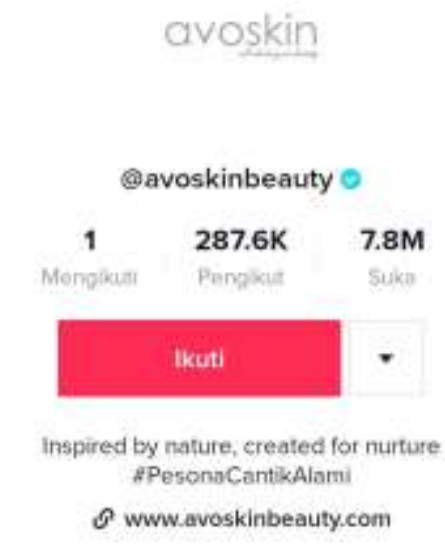

Gambar 3. Akun TikTok Avoskin

Sumber : https://vt.tiktok.com/ZSeFLA5Em/ (akses pada 19-10-2021)

\section{WhiteLab}

whitelab

@whitelabid

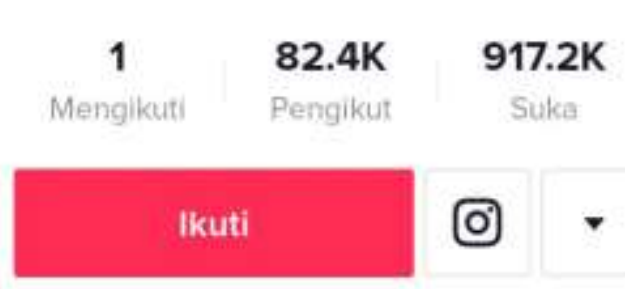

WHITELAB OFFICIAL TIKTOK

Not Your Ordinary Skincare

shopee: Whitelab

$\mathcal{O}$ www.whitelab.co.id

Gambar 4. Akun Tiktok Whitelab

Sumber : https://vt.tiktok.com/ZSeFLNnaY/ (akses pada 19-10-2021) 


\section{Ms Glow}

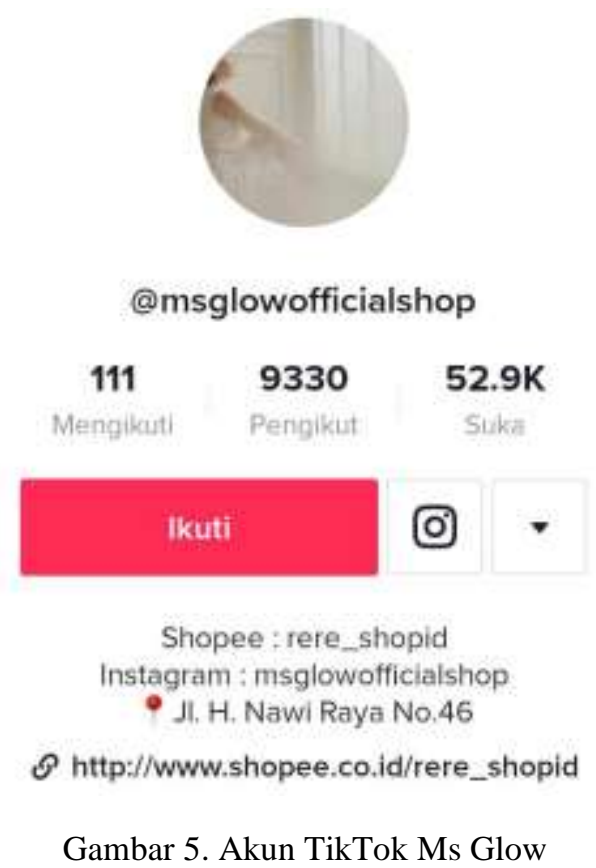

Sumber : https://vt.tiktok.com/ZSeF8o3gg/ (akses pada 19-10-2021)

Dari kelima akun TikTok 5 Brand Skin Care Lokal Indoneisa Terlaris Tahun 2021, peneliti menemukan nilai dari masing-masing variabel yang ada untuk menghitung rasio Video Share to Followers dari setiap akun. Pada akun TikTok terdapat 7 variabel, diantaranya yaitu :

1. Likes

2. Followers

3. Following

4. Video Likes

5. Video Comments

6. Video Share

7. Video Views

Dari ketujuh variabel tersebut peneliti hanya fokus untuk menemukan hasil dari 2 variabel, yaitu :

1. Video Share

2. Followers

Dari kedua variabel tersebut kemudian dianalisa sehingga menemukan nilai rata-rata dari variabel video share dan variabel followers. Untuk menghitung nilai rata-rata dari variabel video share dan variabel followers yaitu dengan cara mengambil minimal 10 postingan kemudian di hitung sehingga menemukan nilai rata-rata dari masing-masing variabel. Berikut merupakan tabel nilai rata-rata dari masing-masing vendor smartphone di Indonesia, yaitu : 
Tabel 1. Analisa Nilai Rata-Rata Nilai Variabel Video Share dan Followers Akun TikTok Somethinc

\begin{tabular}{|c|c|c|}
\hline No & $\begin{array}{c}\text { Video } \\
\text { Share }\end{array}$ & Followers \\
\hline 1 & 58 & 790.300 .000 \\
\hline 2 & 206 & \\
\hline 3 & 103 & \\
\hline 4 & 15 & \\
\hline 5 & 11 & \\
\hline 6 & 40 & \\
\hline 7 & 215 & \\
\hline 8 & 49 & \\
\hline 9 & 19 & \\
\hline 10 & 24 & \\
\hline Total & $\mathbf{7 4}$ & $\mathbf{7 9 0 . 3 0 0 . 0 0 0}$ \\
\hline
\end{tabular}

Sumber : Pengolah Data Excel

Tabel 2. Analisa Nilai Rata-Rata Nilai Variabel Video Share dan Followers Akun TikTok N'PURE

\begin{tabular}{|c|c|c|}
\hline No & $\begin{array}{c}\text { Video } \\
\text { Share }\end{array}$ & Followers \\
\hline 1 & 52 & 73.200 .000 \\
\hline 2 & 28 & \\
\hline 3 & 3 & \\
\hline 4 & 2 & \\
\hline 5 & 1 & \\
\hline 6 & 2 & \\
\hline 7 & 2 & \\
\hline 8 & 20 & \\
\hline 9 & 4 & \\
\hline 10 & 2 & $\mathbf{7 3 . 2 0 0 . 0 0 0}$ \\
\hline Total & $\mathbf{1 1 , 5}$ & \\
\hline \multicolumn{3}{|c|}{ Sumber : Pengolah Data Excel } \\
\hline
\end{tabular}


Tabel 3. Analisa Nilai Rata-Rata Nilai Variabel Video Share dan Followers Akun TikTok Avoskin

\begin{tabular}{|c|c|c|}
\hline No & $\begin{array}{c}\text { Video } \\
\text { Share }\end{array}$ & Followers \\
\hline 1 & 3 & 287.600 .000 \\
\hline 2 & 304 & \\
\hline 3 & 528 & \\
\hline 4 & 25 & \\
\hline 5 & 5 & \\
\hline 6 & 79 & \\
\hline 7 & 3 & \\
\hline 8 & 4 & \\
\hline 9 & 11 & \\
\hline 10 & 32 & \\
\hline Total & \multicolumn{3}{|c|}{$\mathbf{9 9 , 4}$} & $\mathbf{2 8 7 . 6 0 0 . 0 0 0}$ \\
\hline
\end{tabular}

Tabel 4. Analisa Nilai Rata-Rata Nilai Variabel Video Share dan Followers Akun TikTok WhiteLab

\begin{tabular}{|c|c|c|}
\hline No & $\begin{array}{c}\text { Video } \\
\text { Share }\end{array}$ & Followers \\
\hline 1 & 2 & 74.000 .000 \\
\hline 2 & 3 & \\
\hline 3 & 17 & \\
\hline 4 & 11 & \\
\hline 5 & 49 & \\
\hline 6 & 9 & \\
\hline 7 & 17 & \\
\hline 8 & 19 & \\
\hline 9 & 10 & \\
\hline 10 & 73 & \\
\hline Total & $\mathbf{1 7 , 4}$ & $\mathbf{7 4 . 0 0 0 . 0 0 0}$ \\
\hline
\end{tabular}

Sumber : Pengolah Data Excel 
Tabel 5. Analisa Rata-Rata Nilai Variabel Video Comments dan Video Views Akun TikTok Realme Indonesia

\begin{tabular}{|c|c|c|}
\hline No & $\begin{array}{c}\text { Video } \\
\text { Comment }\end{array}$ & $\begin{array}{c}\text { Video } \\
\text { Views }\end{array}$ \\
\hline 1 & 5 & 9.215 \\
\hline 2 & 261 & \\
\hline 3 & 102 & \\
\hline 4 & 131 & \\
\hline 5 & 5 & \\
\hline 6 & 102 & \\
\hline 7 & 129 & \\
\hline 8 & 79 & \\
\hline 9 & 10 & \\
\hline 10 & 10 & \\
\hline Total & $\mathbf{8 3 , 4}$ & $\mathbf{9 . 2 1 5}$ \\
\hline
\end{tabular}

Sumber : Pengolah Data Excel

Setelah menghitung nilai rata-rata tersebut, maka akan menemukan hasil akhir nilai rata-rata dari variabel video comments dan

Tabel 6. Nilai Variabel Pada Akun TikTok 5 Brand Skin Care Lokal Indonesia Terlaris 2021

\begin{tabular}{|l|c|c|c|c|c|}
\hline Variable & Somethinc & N'PURE & Avoskin & White Lab & Ms Glow \\
\hline Video Share & 74 & 11,5 & 99,4 & 17,4 & 83,4 \\
\hline Followers & 790.300 .000 & 73.200 .000 & 287.600 .000 & 74.000 .000 & 9.215 \\
\hline
\end{tabular}

Sumber : Pengolah Data Excel

Pada akun TikTok terdapat 17 rasio yang relevan digunakan untuk mengukur kredibilitas pada masing-masing akun. Namun pada penelitian kali ini hanya berfokus untuk menghitung Video Share to Followers Ratio. Untuk menghitung kredibilitas dari masing-masing akun TikTok setiap vendor skin care, peneliti menghitung dengan cara : variabel 1 akan dibagi dengan variabel 2, sehingga ditemukan hasil analisisa dari rasio tersebut. 
Tabel 7. Hasil Perhitungan Rasio Akun TikTok

\begin{tabular}{|l|l|l|l|l|l|l|}
\hline NO & RATIO & Somethinc & N'PURE & Avoskin & Whitelab & Ms Glow \\
\hline 1 & $\begin{array}{l}\text { Video Comments to } \\
\text { Video Views Ratio }\end{array}$ & 9.3635300 & 1.5710400 & 3.4561900 & 2.3513500 & 0.009050461 \\
\hline
\end{tabular}

Sumber : Pengolah Data Excel

Video Share to Follower Ratio memiliki karakteristik yang tinggi, artinya semakin tinggi nilai yang dihasilkan maka semakin baik kredibilitas dari performa akun tersebut. Untuk memberikan peringkat pada masing-masing Skincare, peneliti memberikan angka 5 kepada vendor yang mendapatkan nilai tertinggi dan angka 1 untuk vendor skin care yang mendapatkan nilai terendah. Berikut merupakan tabel urutan nilai yang dihasilkan oleh masingmasing vendor smartphone.

Tabel 8. Nilai Rasio Akun TikTok 5 Brand Skin Care Lokal Indonesia Terlaris 2021

\begin{tabular}{|c|c|c|c|c|l|}
\hline \multirow{2}{*}{ RATIO } & \multicolumn{5}{|c|}{ NILAI } \\
\cline { 2 - 6 } & Somethinc & N'PURE & Avoskin & Whitelab & $\begin{array}{l}\text { Ms } \\
\text { Glow }\end{array}$ \\
\hline $\begin{array}{l}\text { Video Share to } \\
\text { Followers Ratio }\end{array}$ & 5 & 2 & 4 & 3 & 1 \\
\hline
\end{tabular}

Sumber : Pengolah Data Excel

Dari Tabel Nilai Rasio Akun TikTok 5 Brand Skin Care Lokal Indonesia Terlaris Tahun 2021 dapat simpulkan bahwa Somethinc mendapatkan nilai tertinggi untuk rasio Video Share to Follower Ratio. Sedangkan akun TikTok Ms Glow mendapatkan nilai terendah untuk rasio ini. Jadi, pada penelitian ini Somethinc memiliki kredibilitas performa yang lebih baik dibandingkan dengan vendor skincare yang lainnya. 


\section{KESIMPULAN}

Tujuan dari penelitian ini adalah mengetahui kredibilitas performa dari akun TikTok 5 Brand Skin Care Terlaris di Indonesia menggunakan Video Share to Follower Ratio. 5 Brand Skin Lokal Terlaris Tahun 2021 Di Indonesia. Dari kelima Brand Skin Care Lokal tersebut dapat disimpulkan bahwa :

1. Peringkat pertama diraih oleh Somethinc Indonesia dengan nilai tertinggi yaitu 9.3635300

2. Peringkat kedua diraih oleh Avoskin Indonesia dengan nilai 3.4561900

3. Peringkat ketiga diraih oleh Whitelab Indonesia dengan nilai 2.3513500

4. Peringkat keempat diraih oleh NPURE Indonesia dengan nilai 1.5710400

5. Peringkat kelima diraih oleh MS Glow Indonesia dengan nilai terendah yaitu 0.009050461 


\section{DAFTAR PUSTAKA}

5 Brand Skin Care Lokal Terlaris Tahun 2021. (n.d.). 5 Brand Skin Care Lokal. https://sumsel.tribunnews.com/2021/07/01/5-brand-skincare-lokalindonesia-terlaris-tahun-2021-terbaik-yang-wajib-kalian-coba-bersamateman

Adawiyah, D. P. R. (2020). Pengaruh Penggunaan Aplikasi TikTok Terhadap Kepercayaan Diri Remaja di Kabupaten Sampang. Jurnal Komunikasi, 14(2), 135-148. https://doi.org/10.21107/ilkom.v14i2.7504

Eriyanto. (n.d.). Analisis Jaringan Media Sosial.

Hanasiah, N. (2017). Template Jurnal (pp. 220-228).

Hasiholan, T. P., Pratami, R., \& Wahid, U. (2020). Pemanfaatan Media Sosial Tik Tok Sebagai Media Kampanye Gerakan Cuci Tangan Di Indonesia Untuk Mencegah Covid-19. Communiverse : Jurnal Ilmu Komunikasi, 5(2), 70-80. https://doi.org/10.36341/cmv.v5i2.1278

Merdeka.com. (n.d.). https://www.merdeka.com/.

Nurlailiyah, S. (2016). Studi Dampak Facebook Terhadap Perubahan Pola Komunikasi Antar Pribadi Mahasiswa IAIN Jember.

Pintar, I. (n.d.). https://akupintar.id/info-pintar/-/blogs/sistem-informasigeografis-sig-pengertian-komponen-analisis-dan-fungsi.

Saifuddin Azwar. (2007). Metodologi Penelitian. i, 16-28.

Susilowati. (2018). Pemanfaatan Aplikasi Tiktok Sebagai Personal Branding Di Instagram. Jurnal Komunikasi, 9(2), 176-185. https://ejournal.bsi.ac.id/ejurnal/index.php/jkom/article/viewFile/4319/2703 